\title{
Modular phakoemulsification training adapted for a left-handed trainee
}

\begin{abstract}
Background The increasing demand for high-volume, high-quality cataract surgery creates additional challenges for surgeons providing phakoemulsification training. We describe the modular training programme used by the Worcester Eye Department for inexperienced trainees and the adaptation of this programme to the needs of a left-handed trainee.

Methods The intraoperative complications of a left-handed trainees' first 161 cases are reported.

Results In this series, there was one case of vitreous loss $(0.62 \%)$ and one case of posterior capsular tear $(0.62 \%)$. Two cases developed stable anterior capsular tears $\mathbf{( 1 . 2 4 \% )}$ ) and two cases required a single suture to ensure wound stability.

Conclusion We demonstrate a safe, effective and flexible method of phakoemulsification training.

Eye (2004) 18, 35-37. doi:10.1038/sj.eye.6700528
\end{abstract}

Keywords: left-handed; cataract surgery; phakoemulsification; training

\section{Introduction}

Achieving expertise in phakoemulsification is a challenge for any surgeon-in-training. There is increasing demand for high-volume cataract surgery combined with an increasing expectation of a consistently good visual outcome. To satisfy this demand, modern cataract surgery should encompass both spherical and astigmatic targeting. This creates additional pressures on both trainer and trainee to minimise complications during the learning curve while providing bespoke refractive cataract surgery during high-volume lists.

MJ Freeman', J Singh², P Chell ${ }^{2}$ and K Barber ${ }^{2}$

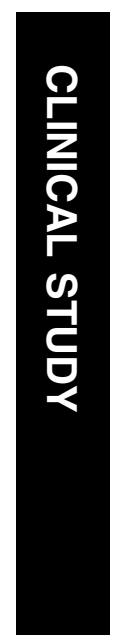

There is increasing concern that trainees in the senior house officer ( $\mathrm{SHO}$ ) grade in the UK have inadequate exposure to surgical training. This was quantified by a survey of SHOs carried out by the Royal College of Ophthalmologists ${ }^{1}$ in autumn 1999. This revealed that $30.7 \%$ of respondents had not performed any surgery in the preceding month and $46.4 \%$ had not performed any phakoemulsification.

Unfortunately, the Action on Cataracts document, produced by the NHS Executive ${ }^{2}$ in 2000, makes very little reference to trainees and provides no practical solutions.

We describe the modular phakoemulsification training programme provided for inexperienced senior house officers at the Worcester Eye Department. The training programme was designed to fit within the department's protocol of seven phakoemulsification procedures per list with six lists per week performed by two senior surgeons. We discuss the practical theory of adapting the training for a left-handed trainee with no previous phakoemulsification experience. The complication rates are compared to previous reports that have documented the phakoemulsification complication rates of trainees in the $\mathrm{UK}^{3,4}$ and other centres. $^{5-12}$

\section{Patients and methods}

Data were collected prospectively on the first 161 patients undergoing phakoemulsification performed by a single left-handed surgeon-in-training over an 8-month period between November 1999 and July 2001. The trainee, a third year $\mathrm{SHO}$, had performed 14 extracapsular cataract extractions under supervision prior to this study. They had assisted in phakoemulsification procedures but had no previous hands-on experience. Before performing surgery on patients, they were made familiar with all the equipment involved
${ }^{1}$ Birmingham and Midland Eye centre

City Hospital NHS Trust

Dudley Road

Birmingham, UK

${ }^{2}$ Worcester Eye Department Worcester Royal Infirmary Worcester, UK

Correspondence:

MJ Freeman

Birmingham and Midland Eye centre

City Hospital NHS Trtust Dudley Road

Birmingham B18 7QH, UK

Tel: + 441215543801

Fax: + 441215076791

E-mail: marcecjam@

hotmail.com

Received: 19 November 2002

Accepted in revised form: 6 February 2003 
in the phakcoemulsification procedure and given the opportunity to use wet-lab facilities and attend appropriate microsurgical wet-lab courses.

The selection of patients suitable for a trainee on the learning curve was at the discretion of the senior surgeon. They were all assessed by the senior surgeon at a preoperative assessment clinic within the week before surgery. This process excluded patients with dense nuclear sclerosis, limited vision in the fellow eye, poorly dilating pupils and coincidental pathology complicating the procedure. The trainee completed one step in the procedure as defined in their modular phakoemulsification training programme. The procedures were supervised by a senior surgeon, who completed the remaining steps. All procedures were performed under local anaesthetic. Intraoperative complications were recorded at the time of surgery.

For modular training, the phakoemulsification procedure is divided into steps, which each require the acquisition of skills of increasing technical difficulty (Table 1). The trainee works through the programme from step 1 to step 6 , including the subdivisions of step 5 . High-volume surgery allows for frequent repetition of these steps until both trainer and trainee agree that they have been mastered. The trainer has the flexibility of controlling the number of repetitions required depending on the ability of each trainee. Once step 6 has been completed, the modules can be combined in appropriate permutations until the trainer is confident that the trainee can complete a full procedure safely. The aim is to produce a surgeon that has carefully considered and practised each facet of the phakoemulsification procedure while minimising the risk of operative complications. Training then progresses to the consideration of varying ophthalmic conditions and surgical techniques. The trainee is encouraged to keep a surgical log that records progress through these welldefined modules. This promotes continuity of training when transferring between consultant trainers or between ophthalmology departments.

Table 1 Subdivision of the procedure into modules in a phakoemulsification training programme

Step 1

Step 2

Step 3

Step 4

Step 5
Keratome incision+side-port incision Aspiration of OVD/stromal hydration Irrigation/aspiration of cortex Intraocular lens insertion Phakoemulsification

(a) Initial sculpting

(b) Sculpting+nucleofractis

(c) Quadrant removal $(23 ; 123 ; 1234)$

(d) Complete nucleus removal Capsulorhexis+hydrodissection

OVD, ophthalmic viscosurgical device.

$135^{\circ}$

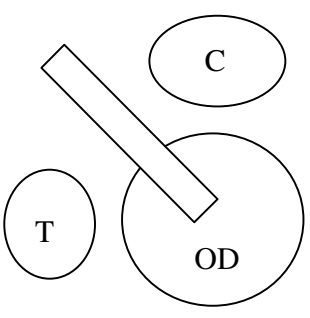

$$
\begin{aligned}
& \mathrm{T}=\text { Trainee } \\
& \mathrm{C}=\text { Consultant }
\end{aligned}
$$

Figure 1 Adaptations of surgeon positioning and incision site for left-handed modular phakoemulsification training.

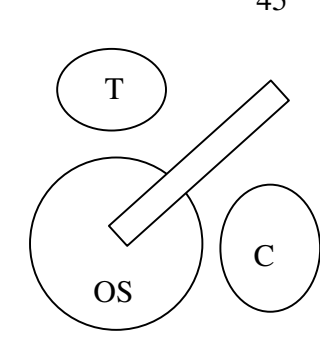
$45^{\circ}$

There are particular considerations when adapting this training to a left-handed trainee (Figure 1). A right-handed trainer operating on a right eye at $10^{\circ}$ cannot easily hand over to a left-handed trainee without the trainee adopting a right-handed approach. Similarly, a right-handed trainer operating on a left eye at $100^{\circ}$ would encounter problems with the handover. To accommodate the left-handed trainee, left-eye cataracts were approached through a clear corneal temporal incision at $45^{\circ}$, allowing the trainee to sit above the patient to perform their step. Right-eye cataracts were approached through a clear corneal superior incision at $135^{\circ}$, with the trainee operating from the temporal side. The position of the one or two additional stab incisions was adjusted for both surgeons to use second instruments comfortably. At each changeover, the merating microscope and phakoemulsification machine als may require adjustment. To facilitate rapid eovers, all theatre personnel need to be familiar training programme.

t-handed training programme can theoretically adapted to encompass training in phakoemulsification ceratotomy using off-meridional and off-meridional approaches. The obliquely crossed cylinders to combine the patient's preoperative corneal plane astigmatism with wound vectors of $0.45 \mathrm{DC}$ at $45^{\circ}$ for right eyes and $135^{\circ}$ for left eyes. The resultant vector becomes the target of the antiastigmatic treatment. An on-meridional approach is confined to oblique preoperative corneal astigmatism that coincides with the oblique training incisions. These modifications would allow training to continue despite the increasing trend towards incorporating preoperative corneal topography and astigmatic reduction planning into routine high-volume cataract surgery. 


\section{Results}

The trainee performed a single step in the first 78 phakoemulsification procedures. The next 25 procedures involved completion of the operation from the phakoemulsification stage (second half) and the final 58 were complete procedures.

The modular phase involved a contribution to a mean of 3.3 cases (range 1-5) during an average operating session of seven phakoemulsification procedures. Despite the apparently cumbersome changeovers from trainer to trainee and back, the planned cases were all completed with no operating list overrunning by more than $15 \mathrm{~min}$.

In 161 cases, there was one episode of vitreous loss $(0.62 \%)$ and one posterior capsular tear with no vitreous loss $(0.62 \%)$. One case was converted to an extracapsular technique $(0.62 \%)$. Two cases developed stable anterior capsular tears $(1.24 \%)$ and two cases required a single suture to ensure wound stability.

\section{Discussion}

Mastering phakoemulsification is central to the training of ophthalmologists. The promotion of high-volume cataract surgery and the pursuit of a perfect refractive outcome have created significant challenges to this training. This has been highlighted as a particular problem for SHOs in the UK in a survey carried out by the Royal College of Ophthalmologists. ${ }^{1}$ Training issues are not adequately addressed in the Action on Cataracts document produced by the NHS Executive. ${ }^{2}$ Many ophthalmology departments are faced with the apparently disparate aims of running a successful cataract service and training inexperienced SHOs.

In the Worcester Eye Department, this has been rationalised by adopting a modular phakoemulsification training programme. This paper demonstrates how this flexible programme was successfully adapted for a left-handed SHO with no prior experience of phakoemulsification. To our knowledge, there are no reports in the literature describing modular phakoemulsification training or adaptations for lefthanded surgeons and antiastigmatic surgery.

There have been various reports describing intraoperative complications and visual outcomes of phakoemulsification performed by residents and SHOs. ${ }^{3-12}$ These studies report posterior capsule tears in $2.1-9.9 \%$ of cases and vitreous loss in $1.8-14.7 \%$ of cases. Our results compare favourably, with a posterior capsule tear rate of $0.62 \%$ (one case) and a vitreous loss rate of $0.62 \%$ (one case). The trainees in these studies are likely to have performed a greater proportion of each procedure than in the early phases of our modular programme. Nonetheless, the comparison emphasises the low complication rate with the modular approach.

We have demonstrated that modular phakoemulsification training adapted for a left-handed trainee is safe and successful. High-volume cataract surgery enhances this approach as it allows for frequent repetition of the individual steps. This repetition under close supervision minimises complications and maximises the trainee's understanding of the new skills required for phakoemulsification. The trainer can control the rate of progression depending on his or her assessment of each trainee's ability. Antiastigmatic surgery could easily be incorporated and become part of the training programme. Preoperative on- or off-meridional vector incision planning using the standard $135^{\circ}$ and $45^{\circ}$ lefthanded training incisions would allow antiastigmatic treatment to continue during training lists.

\section{References}

1 Are SHO's being exposed to adequate surgical training? Royal college of Ophthalmologists. Training News 2000: issue 5: 1-2. (Supplement to College News. Quarterly Bulletin of the Royal College of Ophthalmologists 2000; Spring.)

2 NHS Executive. Action on Cataracts: Good Practice Guidance. NHS Executive: Leeds, 2000.

3 Tabandeh H, Smeets B, Teimory M, Seward H. Learning phacoemulsification: the surgeon-in-training. Eye 1994; 8: 475-477.

4 Prasad S. Phacoemulsification learning curve: experience of two junior trainee ophthalmologists. J Cataract Refract Surg 1998; 24: 73-77.

5 Corey RP, Olson RJ. Surgical outcomes of cataract extractions performed by resident surgeons using phacoemulsification. J Cataract Refract Surg 1998; 24: 66-72.

6 Cruz OA, Wallace GW, Gay LA, Matoba AY, Koch DD. Visual results and complications of phacoemulsification with implantation performed by ophthalmology residents. Ophthalmology 1992; 99: 448-452.

7 Badoza DA, Jure T, Zunino LA, Argento CJ. State-of-the-art phacoemulsification performed by residents in Buenos Aires, Argentina. J Cataract Refract Surg 1999; 25: 1651-1655.

8 Albanis CV, Dwyer MA, Ernest JT. Outcomes of extracapsular cataract extraction and phacoemulsification performed in a university training programme. Ophthalmic Surg Lasers 1998; 29(8): 643-648.

9 Smith JH, Seiff SR. Outcomes of cataract surgery by residents at a public county hospital. Am J Ophthalmol 1997; 123(4): 448-454.

10 Tarbet KJ, Mamalis N, Theurer J, Jones BD, Olson RJ. Complications and results of phacoemulsification performed by residents. J Cataract Refract Surg 1995; 21(6): 661-665.

11 Noecker RJ, Allinson RW, Snyder RW. Resident phacoemulsification experience using the in situ nuclear fracture technique. Ophthalmic Surg 1994; 25: 216-221.

12 Allinson RW, Metrikin D, Fante R. Incidence of vitreous loss among third year residents performing phacoemulsification. Ophthalmology 1992; 99: 726-730. 